\title{
High basal heat-shock protein expression in bats confers resistance to cellular heat/oxidative stress
}

\author{
Yok Teng Chionh ${ }^{1}$ • Jie Cui ${ }^{2}$. Javier Koh ${ }^{3}$ • Ian H. Mendenhall ${ }^{1}$. Justin H. J. Ng $^{1}$ • Dolyce Low ${ }^{1} \cdot$ Koji Itahana $^{3}$. \\ Aaron T. Irving ${ }^{1}$ (D) $\cdot$ Lin-Fa Wang ${ }^{1}$
}

Received: 20 February 2019 /Revised: 29 April 2019 / Accepted: 29 May 2019 / Published online: 22 June 2019

(C) Cell Stress Society International 2019

\begin{abstract}
Bats, unique among mammals with powered flight, have many species with the longest size-proportionate lifespan of all mammals. Evolutionary adaptations would have been required to survive the elevated body temperatures during flight. Heat shock protein (HSP), highly conserved master regulators of cell stress, expression was examined across tissues and various cell lines in bats. Basal expression level of major HSPs (HSP70 and HSP90) is significantly higher in two different bat species compared to other mammals. This HSP expression could be a bat-unique, key factor to modulate cellular stress and death. Consequently, bat cells survive prolonged heat treatment, along with other stress stimuli, in a HSP-dependent manner, whereas other mammalian cells succumbed. This suggests HSP expression in bats could be an important adaption to intrinsic metabolic stresses like flight and therefore an important model to study stress resilience and longevity in general.
\end{abstract}

Keywords Heat shock proteins $\cdot$ Bat $\cdot$ Flight $\cdot$ Metabolism $\cdot$ Longevity $\cdot$ Virus

\section{Introduction}

Bats are the only mammal that have mastered true flight, and consequently, they must endure elevated body temperatures throughout flight. Additionally, most have longer lifespans than terrestrial mammals of similar body sizes, despite their high metabolic rate and its predicted consequences on oxidative metabolism. As such, they have one of the greatest disparities between body mass and longevity (Ball et al. 2018; Bozek et al. 2017; Davies et al. 2014; Hughes et al. 2018;

Electronic supplementary material The online version of this article (https://doi.org/10.1007/s12192-019-01013-y) contains supplementary material, which is available to authorized users.

Aaron T. Irving

aaron.irving@duke-nus.edu.sg

Lin-Fa Wang

linfa.wang@duke-nus.edu.sg

1 Programme in Emerging Infectious Disease, Duke-NUS Medical School, 8 College Road, Singapore 169857, Singapore

2 Wuhan Institute of Virology, Chinese Academy of Sciences, Wuhan 430071, China

3 Programme in Cancer \& Stem Cell Biology, Duke-NUS Medical School, 8 College Road, Singapore 169857, Singapore
Munshi-South and Wilkinson 2010; Wilkinson and Adams 2019). Their longevity has been attributed, at least in part, to enhanced oxidative stress resistance and protein homeostasis (Salmon et al. 2009; Yin et al. 2016). The body temperature of bats raises drastically during flight (O'Shea et al. 2014), and there is an excessive increase in metabolic rate and presumably oxidative stress, with heart rates up to $1200 \mathrm{bpm}$ (O'Mara et al. 2017; Podlutsky et al. 2005). Anecdotal evidence from carers suggests that fruit bats can tolerate prolonged heat stress in the wild if they remain well hydrated.

Heat shock proteins (HSPs), as evident from their namesake, are produced in response to high temperature though also from other stress responses. There are five general classes: HSP30/40 (DNAJs), HSP60 (HSPD), HSP70 (HSPA1/4/ 5/8/9), HSP90 and small HSPs. Heat shock protein 70 (HSP70) and 90 (HSP90) are among the better characterized HSPs. A key function of HSPs is to react to environmental and physiological stress, bind and repair damaged proteins, and reestablish protein homeostasis. High levels of HSPs have been observed in several long-lived animals (Morley and Morimoto 2004; Salway et al. 2011; Singh et al. 2006). This could be due to the enhanced protein repair mechanisms facilitated by increased HSP levels, limiting prolonged cellular damage (Galbadage and Hartman 2008; Heidler et al. 2010; Minois et al. 1999; Salmon et al. 2009; Swindell 2009; Walker and 
Lithgow 2003; Zhao et al. 2005). Both HSP70 (Beere et al. 2000) and 90 (Pandey et al. 2000) have been shown to inhibit apoptosis by interfering with the formation of the apoptosome, thereby reducing cell death during heat shock (Mosser et al. 1997).

HSPs, often neglected by immunologists, interact with vital components of both the innate and adaptive immune systems (Srivastava 2002). HSP70 and 90 are also up-regulated during viral infection (Geller et al. 2012; Glotzer et al. 2000; Nagy et al. 2011). It is now well-established that bats are reservoirs for several viruses capable of crossing the species barriers, evident by recent outbreaks of related viruses including Ebola virus (Leroy et al. 2005), SARS coronavirus (Li et al. 2005), MERS coronavirus (Ithete et al. 2013), and directly with Nipah virus (Chua et al. 2002) and Hendra virus (Halpin et al. 2000; Young et al. 1996). These viruses often cause severe morbidity and mortality in incidental mammals, while bats remain clinically asymptomatic upon infection (Storm, 2018 \#74; Schuh, 2018 \#73; Schuh, 2017 \#75). Throughout evolution, bats may have gained novel functions allowing them to coexist with these viruses, thus evading the onset of severe pathology (Wynne et al 2014, Zhang et al. 2017; Zhou et al 2016). HSP70 has been shown to inhibit 'cytokine storm', induced by viruses like SARS (Huang et al. 2005), through binding/degrading the p65 subunit of $\mathrm{NF} \kappa \mathrm{B}$, thus reducing overall inflammation and pathology (Tanaka et al. 2014).

Here, we show that bats have elevated expression of heat shock proteins (HSPs) in various tissue and cell lines from two species, comparative sequence analysis of HSPs from ten bat species and that increased HSP expression in vitro confers survival of cells during prolonged heat stress. This evolutionary advantage aids in bat physiology, though, and may have considerable impacts on other unique aspects of bat's longevity and zoonotic potential. The two species characterized include the Australian black flying fox (Pteropus alecto) and the cave nectar bat (Eonycteris spelaea). Both animals are frugivorous in nature, feeding mostly on nectar, flowers, seeds and fruit and are considered long-lived at 19.7 years $(670.1 \mathrm{~g})$ and 22 years (58.7 g), respectively (Wilkinson and Adams 2019 \#59). These bats are largely data deficient with regard to maximum age, and closely related species are documented with much longer lifespans. Both are in the order Yinpterochiroptera and are considered adept at flying with single-day flight ranges documented of over 40 km (Nowak 1999 \#78; Hall 2000 \#77). Both species have similar blood glucose levels and respiratory capacity (/body size), suggesting similar metabolism between the two (Maina 1991 \#82; Hill 1984 \#81; Peng 2017 \#79). We hypothesise that higher levels of HSPs allow bats to endure the metabolic stresses induced by high temperatures, presumably that generated by sustained flight, and this alters the ability of bats to survive at these temperatures. This in turn may impact the bat's lifespan (Podlutsky et al. 2005) and pathogen-host equilibrium as HSPs are involved in both processes (Salmon et al. 2009). The evolutionary conserved function of HSP's does not appear to be altered, merely the regulation of expression and intrinsic availability.

\section{Materials and methods}

\section{Animals and cells}

Healthy Eyonicteris spelaea, Rattus tanezumi, Chalcophaps indica and Treron vernans were caught in Singapore at the beginning of an activity cycle and rested prior to processing. All work was done with the ethics approval of National University of Singapore (IACUC Permit \# B01/12), and the National Parks permits NP/RP11-011-3a and NP/RP12-004-2. All C57BL/6 mice were healthy, male, $8-15$ weeks old. Healthy resting, adult, bats were used for E. spelaea tissue, and samples were obtained from 1 female and 2 males, with an average weight of $58 \mathrm{~g}$. Adult Pteropus alecto bats, physically damaged but otherwise healthy, were collected from bat carers around South-East Queensland (Australia), transiently housed and processed at the resting state. Three males and 1 female were used for NGS with an average body weight of $692 \mathrm{~g}$. These weights are close to the expected weights for these species (Wilkinson and Adams 2019 \#59). All experiments were performed in accordance with relevant guidelines and regulations. The generation of PaLuT02 (RRID:CVCL_DR91) and PaKiT03 (RRID:CVCL_DR89) cell lines has been described previously (Crameri et al. 2009). Eonycteris spelaea lung epithelia (EsLuT02) cell line was generated following our previously established method (Crameri et al. 2009) and selected for based on optimum culturing conditions matching those of most mammalian cells. This cell line exhibits a typical doubling time of 2-3 days, expresses no detectable HIF $1 \alpha$, minimal cellular/ mitochondrial ROS production, and minimal uptake of trypan blue or PI and has been culture up to at least 70 passages, indicating suitable culturing conditions. PaKi, EsLu, BHK-21 (Mesocricetus auratus, RRID:CVCL_1915), MDCK (Canis lupus familiaris, RRID:CVCL_B033), A549 (human, RRID:CVCL_0023) and WI-38 (human, RRID:CVCL_0579) cell lines were all cultured in DMEM (Gibco) with $10 \%(v / v)$ FBS (BioInd \#04-001-1A) (well established for long-term culture). Duck embryo cell-line CCL-141 from Anas platyrhynchus domesticus (RRID:CVCL_T281) was purchased from ATCC and cultured in Eagle's minimum essential medium (EMEM) (Gibco) with 10\% FBS, as recommended. All tissue was preserved in RNALater except for muscle, which was snap frozen in liquid nitrogen then processed with TRIzol directly to preserve the limited RNA amounts. All the tissue samples tested are performed in biological replicates unless otherwise stated. Cell-line studies were performed across multiple passages in separate experiments. 


\section{Heat treatment with siRNA knockdown}

PaKi, BHK and MDCK cells were all initially grown and adhered overnight to 96-well black-wall TC-treated plates (NUNC) at $37{ }^{\circ} \mathrm{C}$ and heat-treated at $40{ }^{\circ} \mathrm{C}$ for $4-24 \mathrm{~h}$. Prior to treatment, cells were loaded at $37^{\circ} \mathrm{C}$ with Vybrant Cell Metabolic Assay Kit with C12-resazurin (Thermo Fisher Scientific), according to the manufacturer's protocol (1:2000), washed twice in PBS and fresh phenol-red free DMEM was added (GIBCO, ThermoScientific). Briefly, the C12-resazurin is converted to a fluorescent by-product by cellular esterases in an ATP-dependent manner, and the fluorescence signal is proportional to the amount of ATP. C12-resazurin by-product was then measured with an excitation/emission maxima of 563/ $587 \mathrm{~nm}$. Enough un-converted dye is loaded for $24 \mathrm{~h}$ of constant imaging accounting for minor bleaching. Fluorescent signal of the converted Resorufin control was the same at 37/ $40{ }^{\circ} \mathrm{C}$. Knockdown of HSP90 and HSP70 by siRNAs was performed using RNAiMAX (Thermo Fisher Scientific) with oligos purchased from IDT (Table S4) according to the manufacturer's protocol. For siRNA knockdown of HSP90, a combination of $H S P 90 A A l$ and $A B 1$ was used at a ratio of 1:1. Cells were washed twice with PBS to remove excess dye and cultured in DMEM with $10 \% \mathrm{FBS}$ at $37^{\circ} \mathrm{C}$ and $40{ }^{\circ} \mathrm{C}$ in a Tecan plate reader and detected using Ex/Em at $560 \mathrm{~nm} / 590 \mathrm{~nm}$ wavelength. Cell viability was calculated by normalizing against the 2-h time point after the dye had completely stabilized. The cell viability was plotted over time using GraphPad Prism software and a growth/survival (Kaplan-Meier) curve constructed. The significant difference between the different cell growth curves over time was calculated using two-way ANOVA, Bonferroni multiple comparisons.

\section{Western blot and quantitative real-time PCR (qPCR)}

Snapped frozen tissues were placed in TRIzol ${ }^{\circledR}$ Reagent (Invitrogen) and homogenized using ceramic beads in tissue digester (FastPrep-24" ${ }^{\mathrm{TM}}$, M.P. Biomedical, LLC, Santa Ana California, USA). RNA and protein were extracted according to the manufacturer's protocol. Proteins were solubilized in $1 \%$ SDS with proteinase inhibitors cocktail (Roche) and separated on $10 \%$ or $15 \%$ SDS-PAGE gels and transferred onto to PVDF membranes (Milipore). Membranes were blocked with 5\% skim milk and probed with anti-Hsp90 (AC88 \#ab13492; Abcam), anti-Hsp70 (3a3, \#ab5439; Abcam) or anti-GAPDH (Pierce) overnight. After washing, the membrane is incubated with goat anti-mouse IgG-HRP (Santa Cruz biotechnology) for $2 \mathrm{~h}$. All antibodies are diluted at 1:5000. Membranes were visualized using ECL prime chemiluminescence reagent (GE Healthcare) and a myECL Imager (Thermo Fisher Scientific), with densitometry performed using MyImageAnalysis software (Thermo Fisher Scientific). Abcam anti-Hsp70 and Hsp90 antibodies have been tested against several animal species including human mouse, chicken and fish and is known to bind to the conserved region of HSP70 and HSP90 (mapped in Supplementary Table S1B, C).

Complementary DNA (cDNA) from tissue and cells was made using QuantiTect ${ }^{\circledR}$ Reverse Transcription Kit (QIAGEN). Quantitative PCR (qPCR) was performed to determine mRNA levels of different HSP genes. Reactions were setup using the SensiFAST ${ }^{\mathrm{TM}}$ SYBR No-ROX Kit (Bioline) and assays were run on the CFX96 Touch ${ }^{\mathrm{TM}}$ Real-Time PCR Detection System (Bio-Rad) under the following cycling condition: $95^{\circ} \mathrm{C}$ for $5 \mathrm{~min}$, followed by 40 cycles of $95^{\circ} \mathrm{C}$ for $10 \mathrm{~s}$ and $55^{\circ} \mathrm{C}$ for $30 \mathrm{~s}$, and ending with a melt profile analysis. Relative expression of the targeted gene was determined by REST formula (Pfaffl 2001), relative to housekeeping gene GAPDH. qPCR primers for HSP90AA1, HSP90AB, HSP70 and GAPDH genes are listed in Table S1. GAPDH has previously been shown to be an appropriate housekeeping gene in multiple species and across tissue (Kosir, 2010 \#85; Foss 1998 \#84; Grant 2009 \#83).

\section{Evolutionary and promoter analysis}

The complete coding regions of HSP genes, HSP90AA1, HSP70 and HSP90AB1, across different species were collected from GenBank (http://www.ncbi.nlm.nih.gov/genome) and aligned using ClustalW in STRAP (Gille and Frommel 2001). Three gene data sets were created and each data set contained 18 mammalian species, belonging to seven groups: Bats (Eptesicus fuscus, Pteropus alecto and Myotis davidii), Cetartiodactyla (Bos taurus, Tursiops truncatus and Sus scrofa) , Odd-toed ungulates (Equus caballus and Ceratotherium simum simum), Carnivores (Felis catus and Canis lupus familiaris), Eulipotyphla (Sorex araneus and Erinaceus europaeus), Rodents (Mus musculus, Rattus norvegicus and Spermophilus tridecemlineatus) and Primates (Homo sapiens, Pan troglodytes and Gorilla gorilla). A non-bootstrapped maximum likelihood phylogenetic reconstruction was performed by using PhyML 3.0 (Guindon et al. 2010), under GTR + I + G model. Tests for selection on ancestral HSPs of different taxa were inferred by using PAML 4.8 (Yang 2007), under a free ratio model, which allows each branch having different $\mathrm{dN} / \mathrm{dS}$ (ratio of nonsynonymous to synonymous changes) values. Promoter analysis was performed using the $1500 \mathrm{bp}$ directly upstream of the ATG for bat (XM_006917965.3) and human (NM_005347.5) HSPA5 gene. The sequence was passed through GenePromoterMiner (http://gpminer.mbc.nctu.edu. tw/) and analysed using TRANSFAC binding sites (Core score 1.0, Matrix threshold 0.95) (Lee et al. 2012).

\section{Nitric oxide stress treatment}

Viability of cells was measured at a single timepoint using propidium iodide (PI) exclusion dye assay. Briefly, PaKiT03 cells were transfected with either siRNA control, siRNA for 
HSP70 or siRNA HSP90 and incubated for $24 \mathrm{~h}$ before treatment with Spermine NONOate for $6 \mathrm{~h}$ at concentrations of $0.1,0.25,0.5$ and $1 \mathrm{mM}$, respectively. The media was then removed, replaced with fresh DMEM and incubated for $72 \mathrm{~h}$. Supernatants were collected, floating cells spun down and added to adherent cells followed by incubation with propidium iodide (PI) at a final concentration of $5 \mu \mathrm{g} / \mathrm{ml}$ for 15 min prior to flow cytometry analysis. Spermine NONOate was purchased from Cayman Chemical in powder form. Flow cytometry was conducted using MACSQuant Analyser 10 (Miltenyi Biotec) and laser excitation wavelength was set at $488 \mathrm{~nm}$ and filtered emission at $615 / 50 \mathrm{~nm}$. A total number of 10,000 live cells were analysed per analysis. The percentage of viable cells were calculated using the equation:

Viable cells $(\%)=$ Number of cells (PI-negative) $/$ Number of cells (PI-negative) at $0 \mathrm{mM}$ spermine NONOate treatment from 10,000

\section{RNASeq}

Total RNA was checked using the RNA 6000 LabChip Kit on the Agilent Bioanalyzer (Agilent Technologies, Palo Alto, CA). RNAseq libraries were prepared using Illumina TruSeq Stranded Total RNA with Ribo-Zero Gold kit following the manufacturer's instructions (Illumina, San Diego, CA, USA). Libraries were validated with an Agilent Bioanalyzer (Agilent Technologies, Palo Alto, CA), diluted and applied to an Illumina flow cell using the Illumina cBOT system. Sequencing was performed on an Illumina HiSeq 3000 sequencer at the Duke-NUS Genome Biology Facility with the paired-end 150-bp read option.

After trimming and cleaning for quality assurance (including distribution of reads), all reads were mapped to the P.alecto reference genome (NCBI genome database: ASM32557v1, 1.01) with Bowtie and RSEM abundance estimation was performed (Li et al., 2005 \#86). E. spelaea reads were de novo assembled with Tophat/Cufflinks (Ghosh 2016 \#87), and the FPKM for both Bowtie/RSEM mapped data sets was calculated using Cufflinks. Normalized FPKM values in liver tissue for P.a ( $n=4$ individuals, GSE129377), E.s ( $n=2$ individuals, GSE129199), and public datasets for H.s ( $n=16$ individuals, GSE94660) and M.m. ( $n=9$ individuals, GSE95135) were compared.

\section{Quantification and statistical analysis}

Unless specifically mentioned in the figure legend, all cell experiments were performed in a biological $(n)$ triplicate with multiple experiments. Animal tissue studies involved three individuals for $\mathrm{qPCR} /$ Western blot and multiple individuals (as indicated) for RNASeq. Graphs for qPCR are combined for technical duplicates $\times$ three biological replicates (six values used in each graph), and Western blot quantification
Fig. 1 Survival of bat cells at $40{ }^{\circ} \mathrm{C}$ and expression of HSPs. a Kidney cell lines, Paki (bat), MDCK (canine) and BHK (hamster) were cultured at $37^{\circ} \mathrm{C}$ along with b lung cell lines PaLu (P.a. bat), EsLu (E.s. bat), A549 (human) and viability was measured each $\mathrm{hr}$ for $24 \mathrm{~h}$ with c12-resazurin ATP-conversion. c Kidney cells were subjected to $40{ }^{\circ} \mathrm{C}$ heat treatment for $24 \mathrm{~h}$ along with $\mathbf{d}$ lung cell lines. Statistical significance was calculated using two-way ANOVA (GraphPad Prism software) comparing the cell growth rate over time; $* * * p<0.0001$. f Expression levels of HSP90AA1, g HSP90AB1 and $\mathbf{h} H S P 70$ in various tissue of C57BL/6 mice, wild caught rat (R. tanezumi) and bats (E. spelaea and $P$. alecto) $(n=3)$ were measured using Sybr-Green qPCR (tissues as indicated, relative to GAPDH). i HSP levels in each tissue were combined into an average value for HSP90AA1, HSP90AB1 and HSP70. The expression of HSPs in bats (E. spelaea and P. alecto) was compared against mouse and rat. Error bar denotes standard derivation (SD)

graphs are combined for three separate Western blots. Cell viability assays are a representative experiment out of three separate experiments (in biological triplicate each time with 12 readings per well/replicate). Error is represented as SD unless otherwise stated and $p^{*}<0.05$, ** $p<0.02$, $* * * p<0.01$ for a one-way ANOVA relative to the matched control (bat vs mouse etc. unless indicated in the figure) or students unpaired, two-tailed, $t$ test, as indicated. Graphs were generated using GraphPad Prism, and heatmaps and boxplots were generated in Morpheus (Broad Institute).

\section{Data accessibility}

All data used in this manuscript is available in open source databases (NCBI SRA BioProjects, H.s GSE94660 M.m. GSE95135 P.a GSE129377 E.s GSE129199) or available to authors upon request.

\section{Results}

\section{Survival of bat cells during prolonged heat stress}

To confirm heat tolerance at the cellular level, as predicted by elevated core body temperature during flight, bat cells were subjected to prolonged heat stress. Bat kidney cells (PakiT03) (Crameri et al. 2009) and lung cells PaLu and EsLu were cultured alongside kidney cells from other species (MDCK and BHK) and human lung cells (A549) cells at $37^{\circ} \mathrm{C}$ and $40{ }^{\circ} \mathrm{C}$ for $24 \mathrm{~h}$ of culture. While all six cell lines were able to grow at $37{ }^{\circ} \mathrm{C}$, as indicated by c12-resazurin conversion by ATP (Fig. 1a, b), only bat cells PaKiT03, PaLu and EsLu were able to survive, and even proliferate, for $24 \mathrm{~h}$ at $40{ }^{\circ} \mathrm{C}$ (Fig. 1c, d). The ATP availability assay, c12-resazurin, documents not just cell survival but continuous metabolic activity by the esterase required to generate fluorescence. This highlights a unique ability to tolerate heat stress by bat cells in culture. 

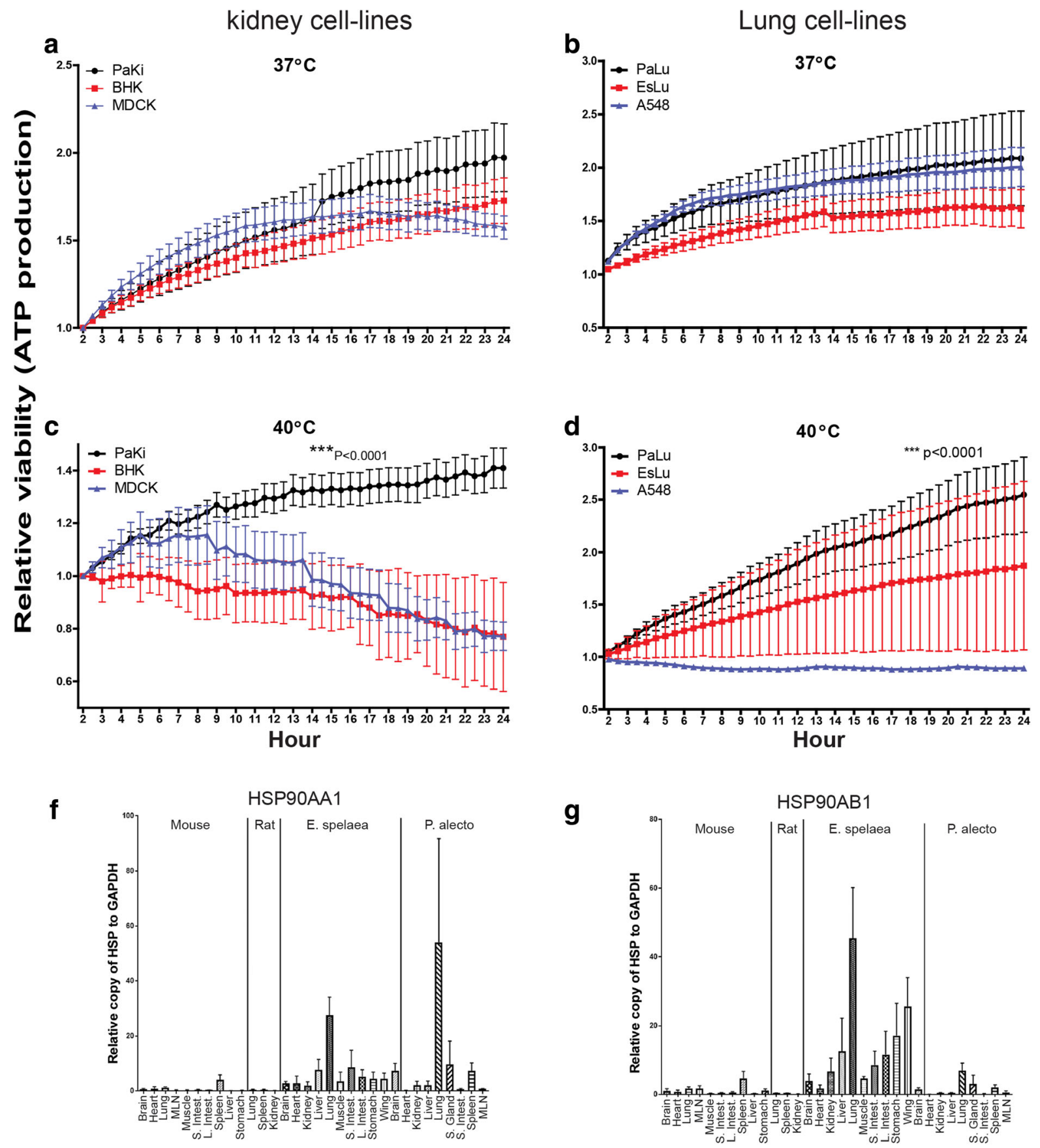

h

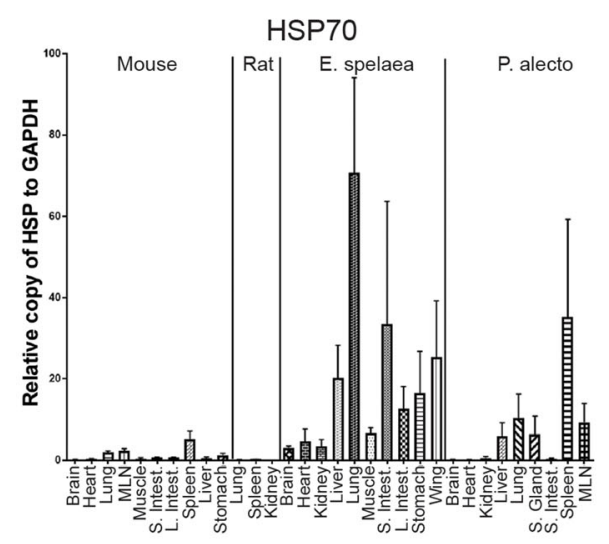

I

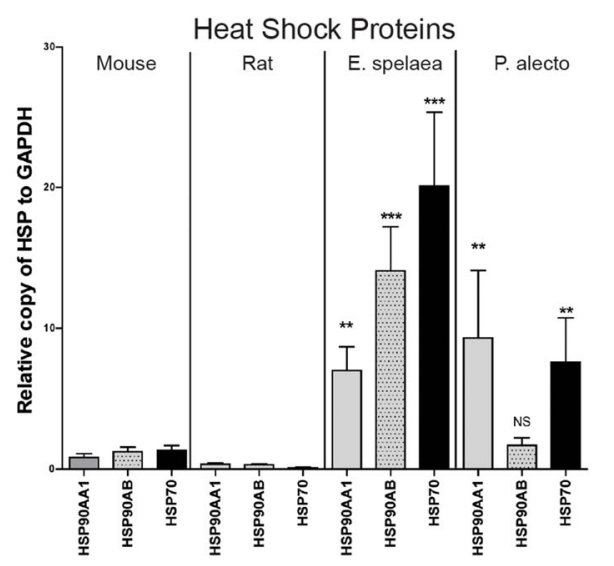




\section{High basal level expression of heat shock proteins in bat tissues}

To determine the level of HSP70 and HSP90 expression in bats, real-time PCR (qPCR) was used to quantify the relative amounts of HSP RNA. As HSP90 involves two different genes (HSP90AA1 and HSP90AB1), we used two qPCR primer sets along with HSP70 (HSPA5) to determine the RNA expression in two bat species, the Singaporean cave nectar bat (Eonycteris spelaea) and the Australian back flying fox (Pteropus alecto). Expression was compared relative to GAPDH, used previously for cross-species/tissue comparison (Ahn 2019 \#90; Kosir 2010 \#85; Foss 1998 \#84; Grant 2009 \#83). Inbred (C57BL/ 6) laboratory mice and wild-captured rats (Asian house rat, Rattus tanezumi) were added for comparison. The additional of a field-captured rodent was to control for any stress response to collection of wild animals and minimize discrepancies between laboratory and wild-caught animals. Tissues tested included heart, lung, spleen, kidney, muscle, brain, liver, intestine, wing and lymph node, collected during the resting state, depending on availability in each species. As shown in Fig. 1f, g, we found that $E$. spelaea, in most tissues, has a significantly higher level of HSP90AA1, HSP90AB and HSP70 compared to rodents. $P$. alecto also has significantly higher levels of HSP90AA1 and HSP70, with a trend for HSP90AB1 that did not reach significance $(p=0.06)$. Figure $1 \mathrm{i}$ shows a cumulative average of the tissues of each species for each gene. All three HSPs are highly expressed in the lung tissues of both E. spelaea and P. alecto (and liver for E. spelaea) compared to those in mice and rats (Fig. 1f-h).

Moreover, we further validated this high HSP expression at the protein level with conserved antibodies known to detect multiple species. This shows that the amount of HSP70 and HSP90 (complex) in both the E. spelaea and P. alecto muscle (at the resting, unstimulated state) is significantly higher compared to mouse, where minimal HSP expression is expected at the resting state (Fig. 2a, antibody binding sites, Table S1).

\section{Differential expression of heat shock proteins across mammalian cell lines}

To confirm in mammalian cell lines (from two different organs, kidney and lung, respectively), we analysed cells by qPCR and Western blot. For kidney, we found that PaKiT03 (bat) cells expressed significantly higher amounts of HSP70 and HSP90A/B both at the mRNA (Fig. 2b-d) and protein levels (Fig. 2e) at $37{ }^{\circ} \mathrm{C}$ compared to the MDCK (dog) and BHK (hamster) cells under normal conditions. Under heat treatment at $40{ }^{\circ} \mathrm{C}$ for $3 \mathrm{~h}$, all kidney-derived cell lines increased the HSP expression at the RNA level (Fig. 2b-d). Interestingly, the relative amounts of HSP70, HSP90AA1 and HSP90AB expressed by PaKiT03 are still significantly higher than those of the other two mammalian cell lines. Similar observations
Fig. 2 Expression at the protein level and correlation to cell line expression. a Protein was extracted from the muscle of C57BL/6 mice, $E$. spelaea and $P$. alecto ( $n=3$ individuals each) using TRIzol extraction method and probed with anti-HSP70, anti-HSP90 and anti-GAPDH antibodies (left panel), and levels were quantified using MyImageAnalysis software (Thermo Fisher Scientific Inc) and normalized against GAPDH (right panel). Statistical significance was calculated using one-way ANOVA (GraphPad Prism software) comparing either E. spelaea or P. alecto to the mouse or rat; $* * * p<0.0001, * * p<0.001$, and $* p<0.05$. Error bar denotes standard derivation (SD). Kidney (MDCK, BHK and PaKi) cell lines were used to determine the expression of $\mathbf{b} H S P 90 A A 1, \mathbf{c} H S P 90 A B 1$ and $\mathbf{d} H S P 70$ by $\mathrm{qPCR}$ as previously at $37{ }^{\circ} \mathrm{C}$ and $40{ }^{\circ} \mathrm{C}$, respectively. e Protein expression of HSP70 and HSP90 in the cell lines at $37^{\circ} \mathrm{C}$ was probed with anti-HSP70, anti-HSP90 and anti-GAPDH antibodies. Similarly, for lung cell lines (A549, W138, PaLu and EsLu) for qPCR (f-h) and protein (i). Statistical significance was calculated using two-way ANOVA (GraphPad Prism software) comparing bat cell lines (PaKiT03, PaLu and EsLu) to other cell lines; $* * p<0.001$, and $* p<0.05$. Error bar denotes standard derivation (SD)

were found in lung-derived cells, as shown in Fig. $2 \mathrm{f}-\mathrm{i}$. With cells maintained basally at $37^{\circ} \mathrm{C}$, bat cells (both $P$. alecto and E. spelaea) produced significantly higher amounts of HSP70 and HSP90 at both mRNA and protein levels than the A549 and WI-38 cells of human origin (Fig. $2 \mathrm{f}-\mathrm{i}$ ). With heat treatment, EsLu and $\mathrm{PaLu}$ cells also produced significantly higher amounts of HSP70, HSP90AAl and HSP90AB compared to A549 and WI-38 cells by qPCR. While maintaining a high basal expression of HSP's, bat cells still retain the ability for further heat induction of HSPs to levels far higher than other mammalian cells.

\section{Sequence conservation and expression differences for selection of bat HSPs}

Proteins with critical functions exhibit high conservation (Castello et al. 2016; Garg et al. 2015; Ng et al. 2016). To determine if this was true for bat HSPs, we analysed the available bat genomic sequences and found a $99.9 \%$ HSP sequence identity between bats and other mammals (Fig. S1). Next, we examined the amino acid selection pressure and found that all three bat HSP genes exhibited slightly higher selection pressure values compared to non-bat mammalian groups (Fig. 3ac); however, this was not statistically significant with the low $\mathrm{dN} / \mathrm{dS}$ ratio inferring that the conservation of genes in this pathway is critical for their function.

To examine expression of HSP 40, 60, 70, 90 and known HSP regulators, de novo transcriptome assembly from liver of wild bats for P. alecto $(n=4)$ and E. spelaea $(n=2)$ was compared with publicly available sequence data of human $(n=16)$ and mouse $(n=9)$ from the same Illumine Hiseq3000 platform/pipeline. The average normalized FPKM is shown (Fig. 3d) with high expression of some HSP70 (particularly HSPA 5/8/9), HSP90 (HSP90AA1/HSP90B1), HSP40 (DNAJA1) and HSP60 (HSPD1) genes in bats compared to 
a

Protein analysis of muscle (western blot)

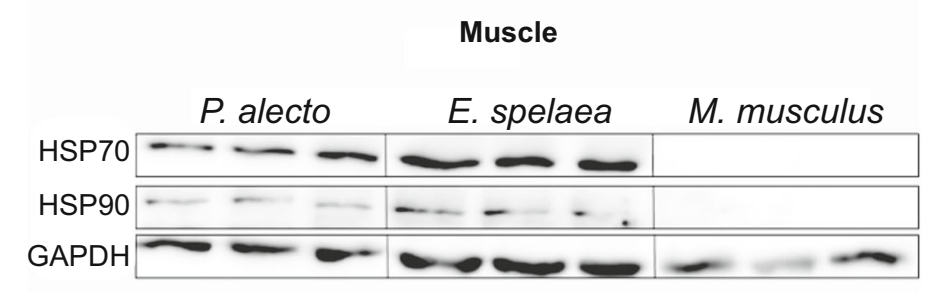

b

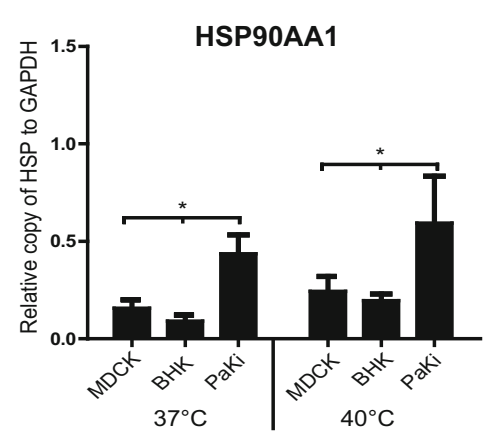

C

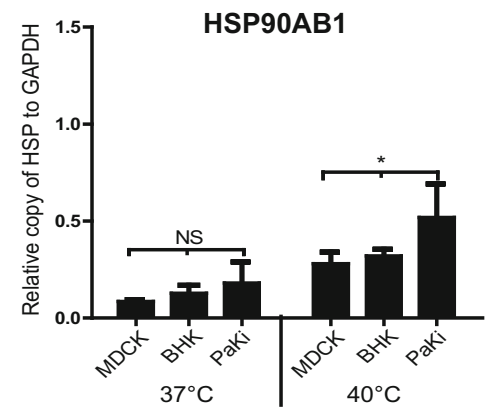

d

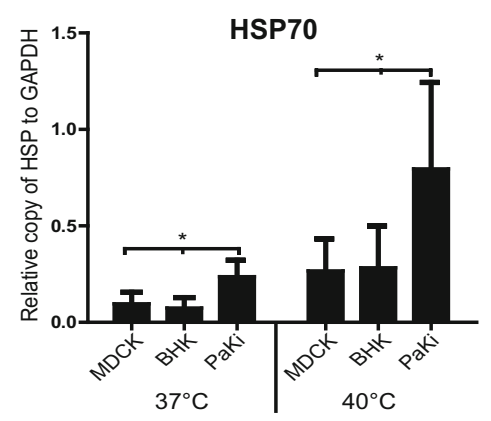

e

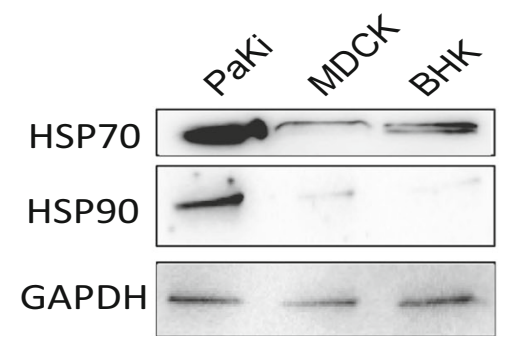

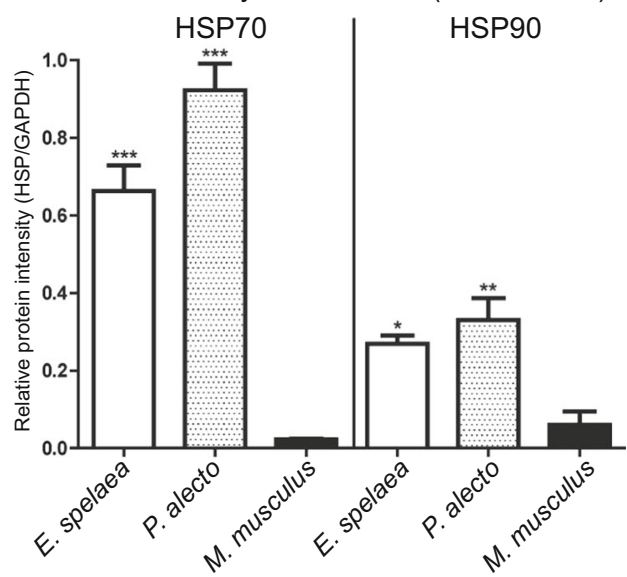

$\mathbf{f}$

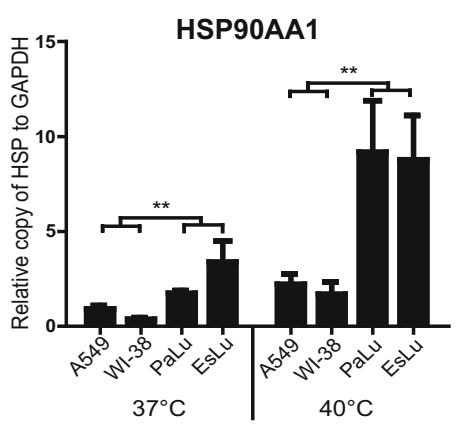

g

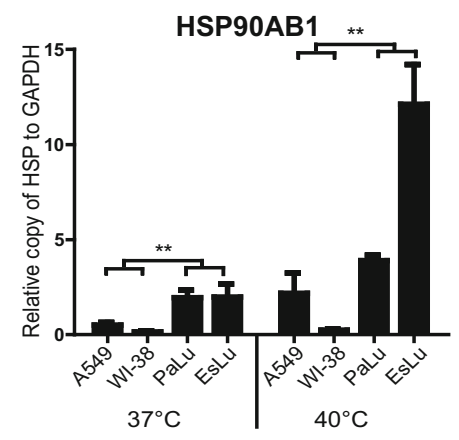

h

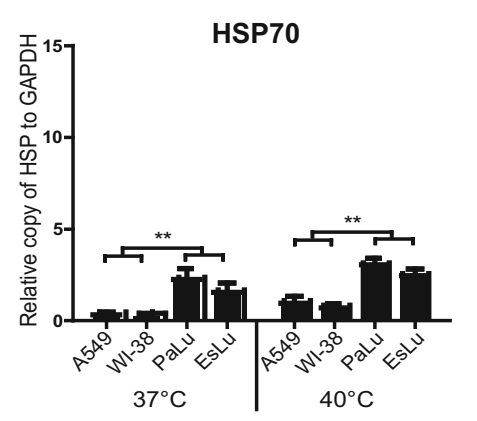

i

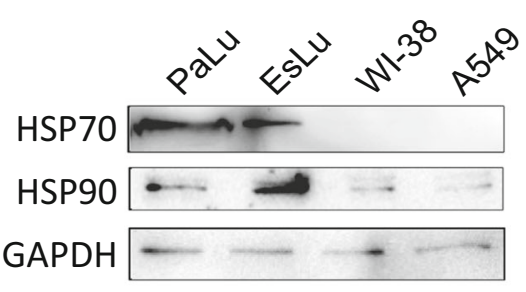


mouse and human (with these significant gene families displayed in the adjacent boxplot). Interestingly, this higher RNA expression does not correlate with the common regulators of HSP expression such as HSF-1/2, PRDM1/4, IRF2, FOS and TP53 (Hayashida et al. 2010; Prasad et al. 2007; Zhang et al. 2011). While there are slightly higher levels of other implicated regulators SMAD1, NFATC1, BACH2, STAT1, MZF1 and NFYA in bat liver tissue, the overall FPKM is still minimal for all regulatory genes except possibly STAT1/MZF1/NFYA (Table S2).

To identify if genetic elements in the promoter are responsible for differential expression, the promoter for human (Hs) HSPA5 (the highest expressed) was analysed (TRANSFAC 8.3.4) and displayed in Fig. 3e. While several elements are missing, or exhibiting lower sequence identity, in the P. alecto (Pa) HSPA5 (Fig. 3f) promoter compared to human, the majority of elements are conserved. There are no obvious additions with new promoter elements/transcription factor (TF) binding sites visible in the PaHSPA5 promoter. Of note, the identity/frequency increased for NFYA/CAAT and MZF1binding sites. Taken together with higher expression of these TFs in the liver, this correlates with higher expression of HSPA5 in bat liver. It is worth to note that in the PaKi and $\mathrm{PaLu}$ cell lines, the expression of most known HSP promoter TFs does not correlate with the high expression of HSP70/90, particularly in comparison to HEK93, which expresses high levels of HSP's concurrent with high levels of most HSF TFs. Table S3 includes NGS FPKM values of HSP genes, TFs and housekeeping genes from PakiT03, PaLu and HEK293 for comparison. There is a slightly elevated level of TP53, MZF1 and NFYA in the bat cell lines that may partially explain the expression status.

\section{Survival of bat cells at $40^{\circ} \mathrm{C}$ is HSP-dependent}

As high basal HSP expression may be responsible for the survival of bat cells at $40{ }^{\circ} \mathrm{C}$, we used siRNA to knockdown HSP 90 and HSP70 in bat PaKT03 and PaLu cells. The knockdown efficiency was determined to be approximately $90 \%$ (Fig. S2). While CrispR-Cas9 can be used in PakiT03 cells, knockdown of HSP90 and HSP70 families via CrispR proved non-viable, likely due to the essential nature of HSPs. However, PaKiT03 and PaLu cells with HSP90 and HSP70 knocked down by siRNA showed minimal signs of abnormal growth (Fig. 4a, b) or morphological change at $37{ }^{\circ} \mathrm{C}$ compared to non-silencing (NS) control siRNA. In contrast, when treated for $24 \mathrm{~h}$ at $40{ }^{\circ} \mathrm{C}$, neither HSP knockdown treatments survived with PaKiT03 or PaLu cells. The control-treatment cells survived and continued to proliferate (Fig. 4c, d). Not only do these findings support the predicted role of HSPs during heat stress, but they also strongly suggest that expression of both HSP70 and HSP90 is essential for the survival of bat cells during this prolonged heat stress.
Fig. 3 Analysis of HSP amino acid selection pressure and regulators of gene expression. The non-synonymous/synonymous (dN/dS) changes of seven major mammalian groups were shown. The values for $H S P 70$ (a), HSP9OAA1 (b) and HSP9OAB1 (c) are calculated using a free-ratio model of which all branches are allowed to have different selection pressures and the values of ancestral branch of each group are exhibited. d Heatmap of normalized FPKM values from de novo assembled transcriptome counts in liver tissue for P.a ( $n=4$ individuals), E.s ( $n=2$ individuals), and public datasets for H.s $(n=16$ individuals, GSE94660) and M.m. $(n=9$ individuals, GSE95135) via Hiseq3000 NGS, scale as indicated (left panel), grey indicates gene not found. The significant genes (HSPA5,8,9, HSP90AA1, HSP90B1, DNAJA1, HSPDI) are graphed as an average boxplot (right panel). e A $1500 \mathrm{bp}$ upstream of the TSS of human HSPA5 was run though TRANSFAC 8.3.4 using TFBind cutoffs, and the identified TF binding sites are indicated. e for Homo sapiens $(H s)$ HSPA5 and (f) for P.a HSPA5. Red indicates a binding identity score > 0.95 , green $0.94>x>0.95$

\section{Comparison of heat shock protein expression in bats and birds}

To further understand the role of HSPs in flying animals, we compared HSP levels of bats with two flying birds, pigeon and dove. Muscle from two avian species were compared against P. alecto (Fig. 4e). P. alecto expressed higher levels of HSP70 and 90 compared to Chalcophaps indica (emerald dove) and Treron vernans (pink-necked green pigeon) (Fig. 4f). The protein levels of HSP70 and 90 in an avian cell line (CCL-141, Anas platyrhynchos domesticus) were also significantly lower compared to PakiT03 (Fig. 4g, h), though albeit than previously examined cells. As we believe high basal HSP expression is a bat-specific adaptation to heat stress, CCL-141 was subsequently cultured at $37^{\circ} \mathrm{C}$ and $40^{\circ} \mathrm{C}$ to examine its resistance to heat stress. While CCL-141 continued to grow at $37^{\circ} \mathrm{C}$, the duck cells stopped growing or dividing at $40^{\circ} \mathrm{C}$ and maintained a constant viability, possibly senescence (Fig. $4 \mathrm{i}$ ).

\section{Knockdown of HSP70 and HSP90 sensitizes PaKiT03 cells to oxidative stress and reduce viability of cells}

As flight of bats is metabolically demanding and high HSP expression is imprinted even in cultured bat cells, we evaluated the protective role of HSPs to oxidative stress that can occur from high metabolic demands. Parental PaKiT03 cells and HSP70 or HSP90 siRNA-treated cells were subjected to increasing concentrations of spermine NONOate for $6 \mathrm{~h}$, followed by incubation for $72 \mathrm{~h}$ and then examined for cell viability. Knockdown of either HSP70 or HSP90 in PaKiT03 cells demonstrated a reduction in cell confluency as assessed via phase-contrast microscopy $72 \mathrm{~h}$ after $1 \mathrm{mM}$ spermine NONOate removal (Fig. S2). In addition, using PI exclusion for viability, we observed significant reduction in the percentage of viable PaKiT03 cells in the presence of HSP70 knockdown for all spermine NONOate concentrations and with 0.1 and $0.25 \mathrm{mM}$ concentrations for HSP90 treatment (Fig. 4j). High doses of spermine NONOate decreased the number of 
a

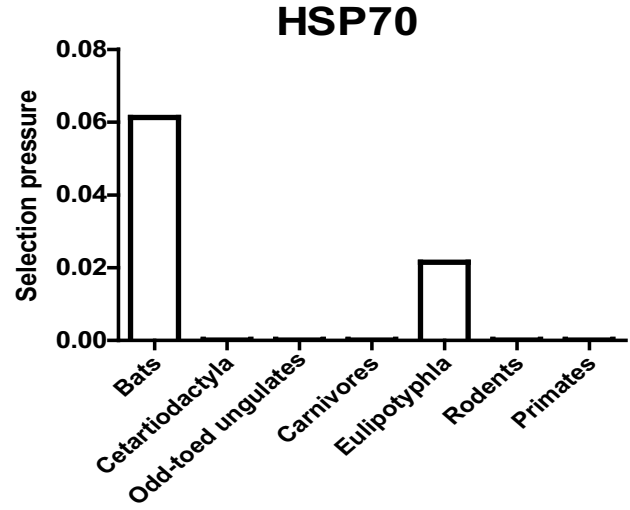

b

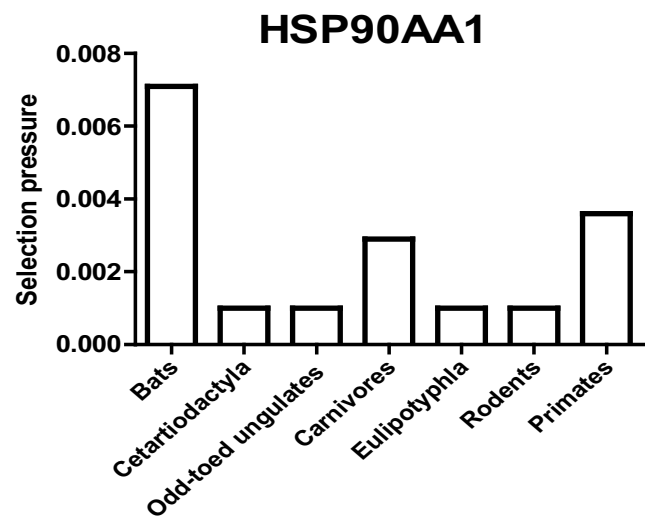

C

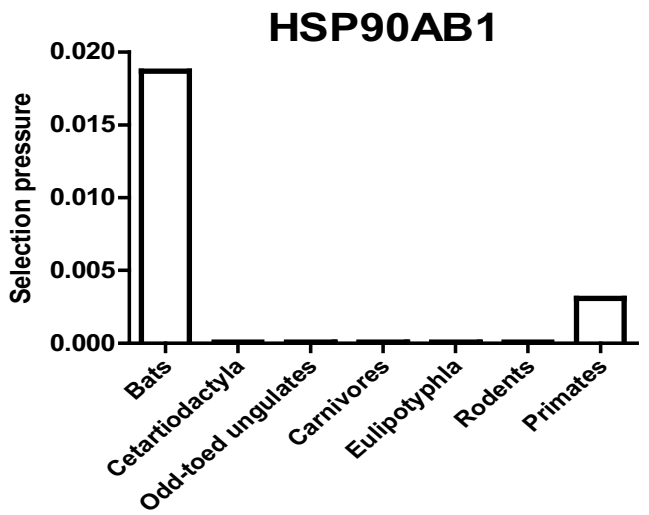

d

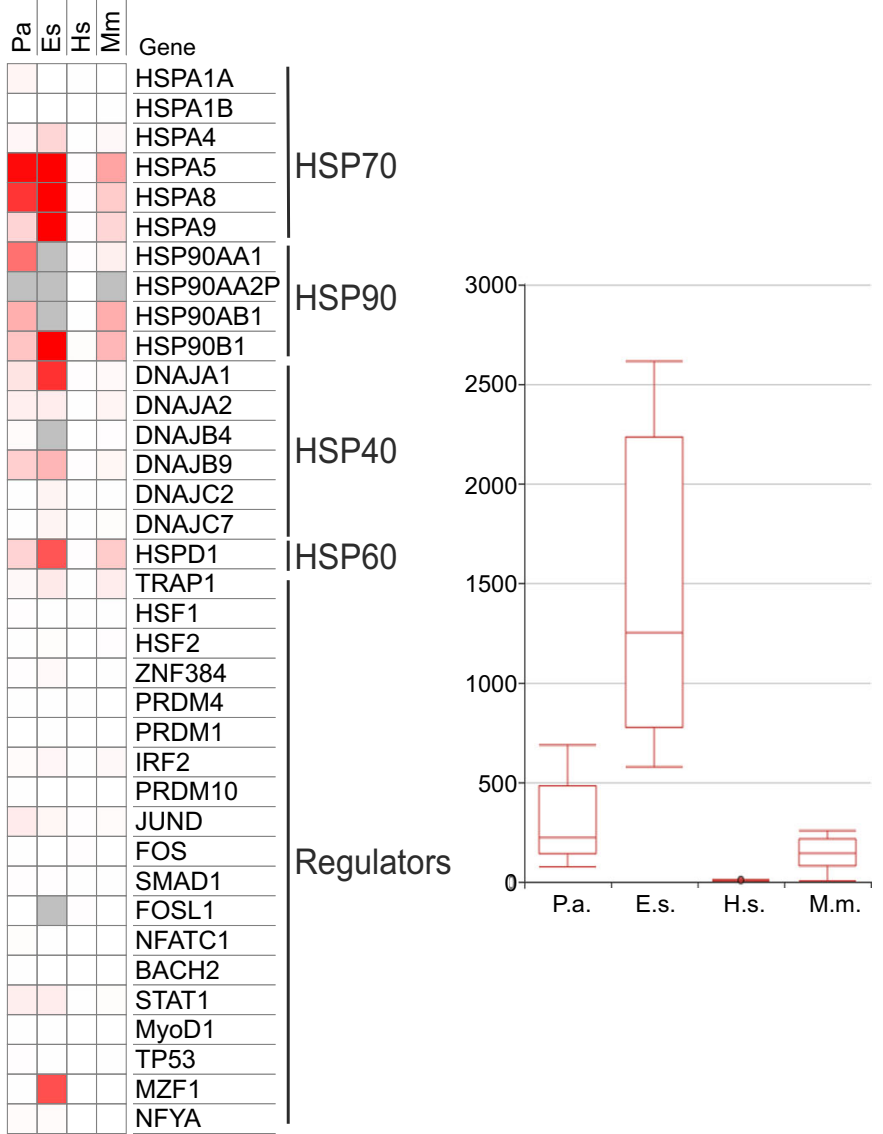

e

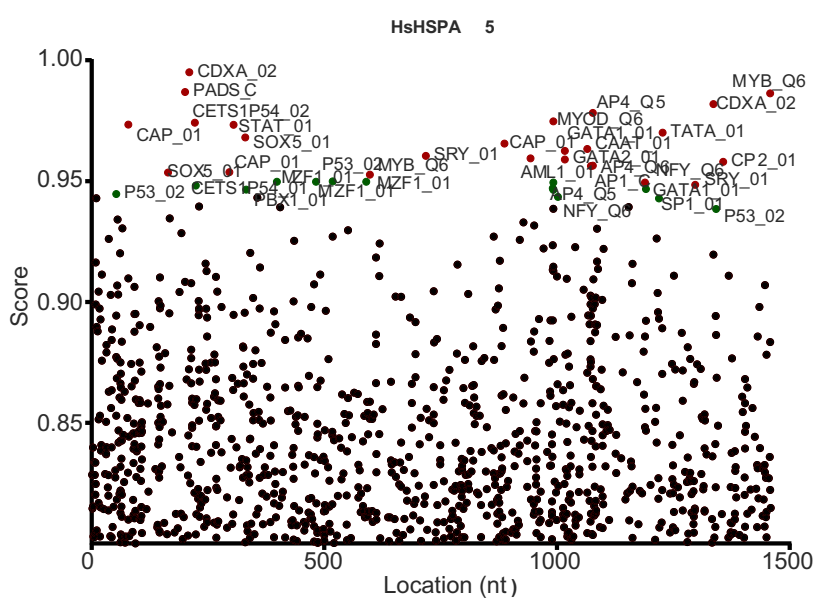

f

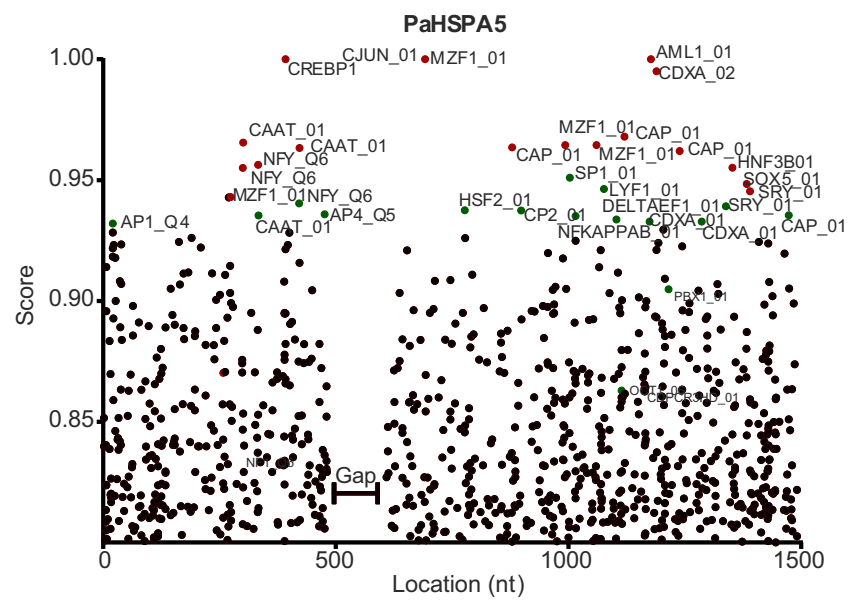


viable cells even in control cells. These observations suggest that HSPs are essential for survivability of bat cells during a type of oxidative stress, nitric oxide, which is potentially generated from flight.

\section{Discussion}

It is conceivable and generally accepted that major evolutionary adaptation is required for bats to sustain its ability to fly. Recent comparative genomics studies have confirmed that bats are different to all other mammalian groups (Ahn et al. 2016; Ng et al. 2016; Zhang et al. 2013; Zhou et al. 2014). However, it is extremely difficult to pinpoint major genetic adaptations to explain why bats have a relatively longer lifespan or to their apparent reservoir host potential. The adaptations required to sustain a high rate of metabolism and high body temperature during daily flight may provide insight. While proving high basal HSP expression of bats is an adaptive evolution from flight is not possible without a non-flying bat species for comparison, we speculate that this high expression pattern of HSPs in bats is likely an adaptation to cope with both high heat and metabolic stress.

Here, we report the first evidence that bats of two different species, $P$. alecto and E. spelaea, have elevated basal level expression of both major HSPs, HSP70 and HSP90, in live animal-derived tissues, and this is imprinted in laboratoryderived cell lines. Additionally, the liver of animals exhibited increased expression of other HSP families including HSP40 (DNAJA1) and HSP60 (HSPD1). Salway et al. (Salway et al. 2011) previously reported that there is a positive correlation between lifespan and the level of HSP expression in animals. In our studies, we have demonstrated that the expression levels of HSP90 and HSP70 are significantly higher than those in the tissue of pigeon, duck, mouse, rat and human and in cell lines of human, dog, hamster and duck origin. This is especially true for HSP70 (HSPA5), which has a 10fold higher level of expression in bats compared to rodents. A comparison to smaller bats with exceptional longevity quotients would be required for a correlation of HSP expression to lifespan in bats. In comparison with other flying animals, pigeon and duck have lower levels of HSP70 and 90 compared to $P$. alecto. This suggests that while birds still increase their core body temperature (McNab 1966) during flight, HSP expression is not be the main protective effector in birds. This suggests that high basal HSP expression is a bat-specific phenomenon. The levels we observed in pigeon and duck are comparable to the study of finches from Salway et al. (Salway et al. 2011). This was partially confirmed by the HSP expression in CCL-141 duck cells failing to confer the resistance to heat stress observed in multiple bat cells. Other primary avian cells have been reported to survive at $40{ }^{\circ} \mathrm{C}$,
Fig. 4 Stress survival in bat and avian cells. a The expression of HSP70 and HSP90 in PaKi cells was reduced using siRNA knockdown and cultured at $37{ }^{\circ} \mathrm{C}$ while tracking cell viability as previous. b As per a but for PaLu cells. c Heat treatment was applied to siRNA-treated PaKi cells at $40{ }^{\circ} \mathrm{C}$ for $24 \mathrm{~h}$ together or to d PaLu cells as per a. Statistical significance was calculated using two-way ANOVA (GraphPad Prism software) comparing the cell growth rate over time; $* * * p<0.0001$. Experiment was performed in triplicate on three separate occasions, and one representative experiment is shown. e Example Western blot for protein expression for bat, duck and pigeon muscle tissue (species as indicated,) and quantified as previous. $\mathbf{f}$ Quantification of expression data for e normalized against GAPDH. Three individuals per species were tested. g Duck cell line CCL-141 was compared to Paki cells by Western blot as per E) (h). Quantification of data in $\mathbf{g}$ relative to GAPDH as previous, three repeats from continuous passages are shown. i Heat-treated viability curves, as described previously, are presented for $37^{\circ} \mathrm{C}$ and $40^{\circ} \mathrm{C}$ for $24 \mathrm{~h}$ of culture relative to the $0 \mathrm{~h}$ timepoint. j siRNAtreated PaKi cells subjected to Na-NONOate treatment for $6 \mathrm{~h}$, followed by incubation for $72 \mathrm{~h}$ total, dose as indicated. Cell survival was measured by PI uptake. Error bar denotes standard derivation (SD)

presumably through HSP-independent mechanisms (Harper, 2011 \#88).

To determine if bat HSPs could functionally differ, we examined genetic evolution and $\mathrm{dN} / \mathrm{dS}$ selection pressure. As bat HSPs are highly homologous to other mammalian HSPs, with low $\mathrm{dN} / \mathrm{dS}$ variation, this seems unlikely and it emphasizes their critical function in the biology of the host. It has previously been shown that there is a disconnection between cross-species sequence homology and expression levels in the oriental fruit moth (Zhang et al. 2016). This highlights that altering expression of HSPs rather than altering the function of HSPs still confers a phenotypic advantage. This may be the case in other species, such as the bat. Further annotation and sequencing data from available bat genomes will allow a full phylogeny-independent characterization of all HSP genes from bats, though our preliminary indicates that HSP function is not altered.

Analysis of the highly expressed HSP70 gene revealed only minor differences in the promoter region with no particularly enhanced elements compared to the human promoter. While caution must be used when using algorithms designed against human on bat transcription factors (TFs), there was an increased number of binding sites above the threshold for the NFYA/CAAT DNA-binding elements and also MZF1. Both of which show higher expression in the liver tissue of both bat species compared to mouse and human. Additionally, there is a 150-bp gap in the genome for the P. alecto promoter, which may mask other binding elements. Intriguingly, HSP expression in bats has been linked to hibernation with increased HSP70 and HSP90 expression observed during Torpor (Zhang et al. 2013). While the species investigated here are not known for hibernation, partial torpor is recorded in most fruit bat species along with resting bradycardia during flight (O'Mara et al. 2017) that resembles partial torpor. This may highlight evolutionary conserved pathways for thermos 
a

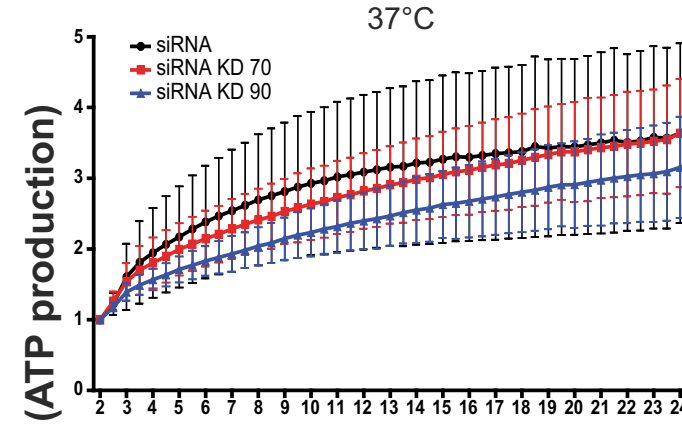

C

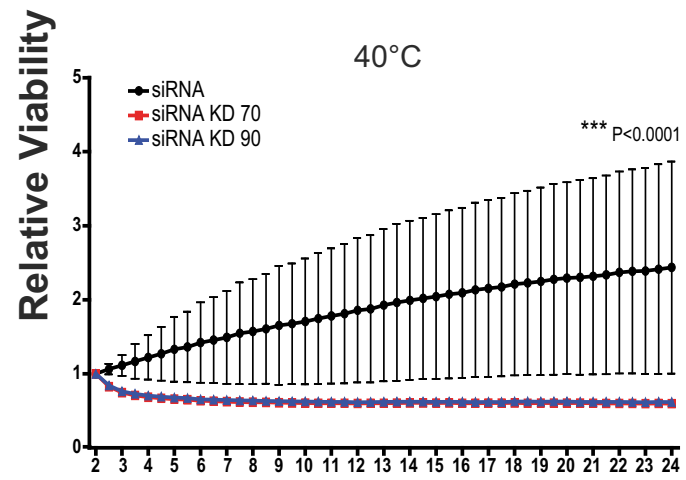

e

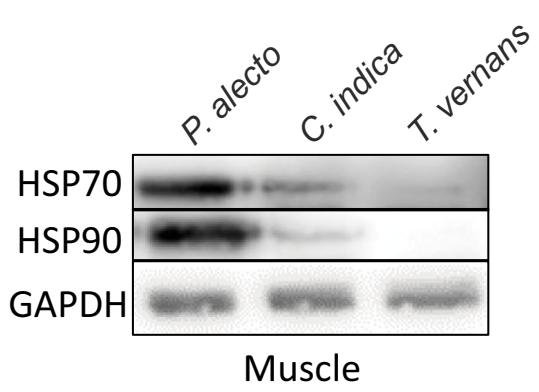

g
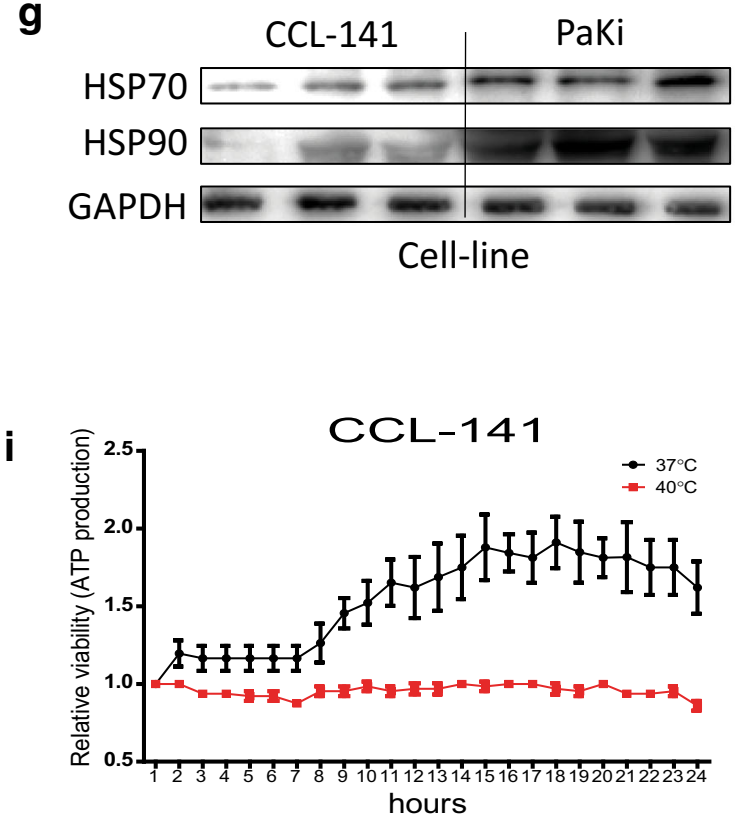

b

PaLu

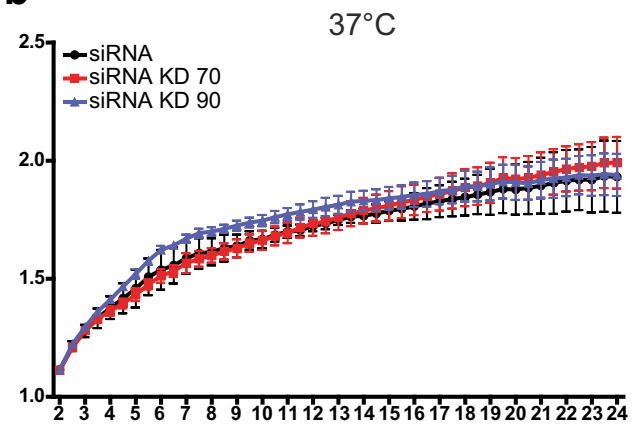

d

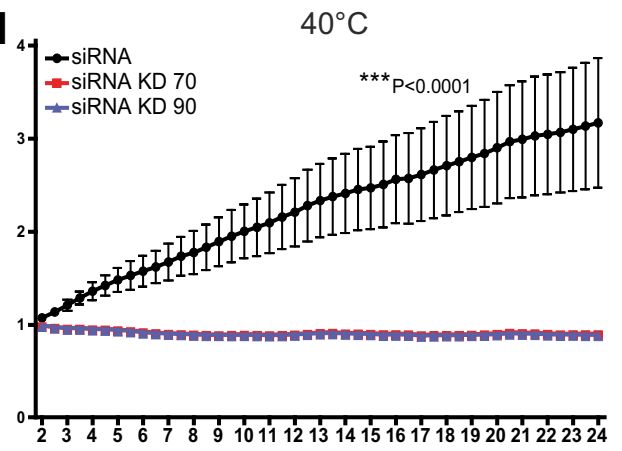

$\mathbf{f}$

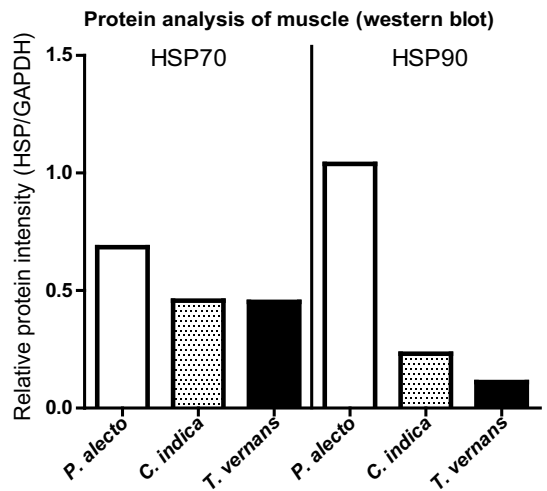

h Protein analysis of cell-lines (western blot)

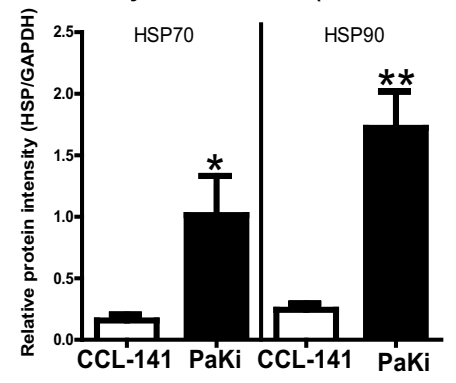

j

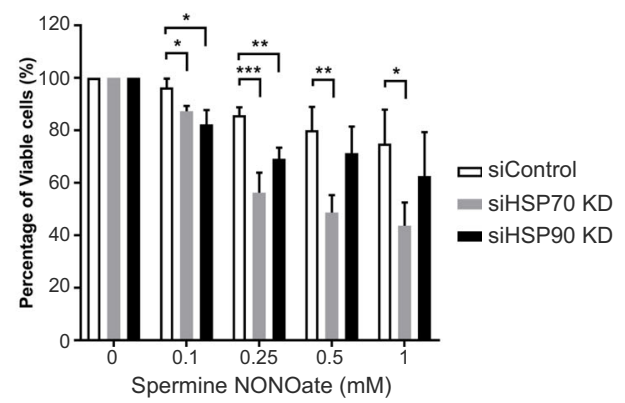


regulation in bats leading to higher expression of HSPs. Indeed, NFYA, a known regulator of HSP 70/90 and a TF expressed higher in bats (Fig. 4d), has also been implicated in torpor (Han et al. 2015). Other additional elements compared to human included GATA, NFAT, ELK1/Ets and MYB binding sites, though these had lower binding scores. A full functional analysis of the promoter elements for each HSP gene in better annotated genomes and the binding capacity of each TF would be required to clarify this alternative, HSF-independent, expression of HSPs in bats.

As HSP expression can be further induced two-fold with heat treatment, similar to non-bat mammalian cells, it suggests that baseline HSP expression in bats is important while retaining endogenous mechanisms for induction with heat shock and likely other stress inducers such as the unfolded protein response. As this is the case, we do not believe before and after flight to be the most significant contribution to HSP expression but rather an imprinted basal expression. That bat cells were no longer able to grow at $40{ }^{\circ} \mathrm{C}$ when either HSP70 or HSP90 was abolished by siRNA and highlights their role in endurance of heat-induced stress in bat cells, whether related to flight or independent. This high base level in vitro confers basal thermo-tolerance. This confirms the known classical function of HSP for resistance to heat-induced apoptosis or cell death (Mosser et al. 1997), largely due to HSP70's ability to bind Apf-1 and prevent recruitment of caspases for the formation of the apoptosome complex (Beere et al. 2000).

Moreover, flight itself is metabolically demanding and could in turn increase cellular oxidative stress, affecting cell survivability. Our data with spermine NONOate treatment, in the absence of heat shock, demonstrated the pro-survival feature of HSP70 and HSP90 in bat cells, although the definitive mechanism remains to be elucidated. The little brown bat Myotis lucifugus, with an estimated lifespan of 34 years (AnAge, http://genomics.senescence.info/species/), can reduce free radicals in their bodies (Brunet-Rossinni 2004). Due to the wide-ranging tissue expression, the role of HSPs in the general protein homeostasis in bats must be considered, along with any possible implication for reduced ageing. This notion is also supported by two recently published studies on the long-lived naked mole rat. While HSPs were highly conserved to other mammals, they observed reduced protein degradation and unfolding despite increased oxidative stress (Perez et al. 2009). Another recent study observed a higher level of HSP70 and HSP25 in the naked mole rat (Rodriguez et al. 2016) possibly enhancing protein repair and reducing cellular damage.

There may be other implications for high HSP expression in explaining why bats are effective hosts to zoonotic viruses (Hu et al. 2014; Miller et al. 2016; Plowright et al. 2015; Zhu et al. 2009). HSP70 can promote Ebola virus replication (Shurtleff et al. 2014). Nipah virus has been shown to utilize HSP90 for chaperoning viral L polymerase (Bloyet et al.
2016), and Dengue virus (DENV) uses HSP70 and HSP90 as alternative receptors for viral entry (Reyes-del Valle et al. 2005). HSP expression also affected the mutation rate/genetic diversity of influenza viruses (Phillips et al. 2017). The basal expression level of several HSP genes is genetically imprinted in vivo in live animal-derived tissues from two species of bat, with cultured cell lines displaying the same high expression. This is required for bat cells to sustain prolonged heat stress and affects their response to oxidative stress. Together with published literature linking high HSP expression level with long lifespan and promotion of virus entry and/or replication, this speculatively links the two most fascinating features of bat biology, i.e. longer lifespan and an exceptional ability as a zoonotic host.

Acknowledgements We wish to acknowledge Gary Crameri and Dr. Michelle Baker at CSIRO/AAHL for access to Pteropus cell lines.

Authors' contributions YTC designed and performed the experiments with JK and ATI. YTC and ATI drafted the manuscript. JC and ATI performed the bioinformatics analysis. IHM and DL helped in the E. spelaea sampling and the establishment of E. spelaea cell lines. JN, YTC and ATI helped in the collection of the P. alecto bat sampling and JN established the $P$. alecto and E. spelaea tissue cDNA libraries. ATI designed the heat treatment assay. KI provided mentorship and funding for JK. JN, ATI and LFW revised the paper and provided scientific insight. All authors read and approved the final manuscript. We acknowledge Tan Jun Hao for his help in amino acid sequence alignment of the HSPs. We thank Gary Crameri and the Queensland Animal Science Precinct team led by Hume Field for their advice and help in catching and handling P. alecto.

Funding This work was supported by grant NRF2012NRF-CRP001056 from the National Research Foundation in Singapore (L-F.W.). IH Mendenhall is supported by a New Investigator's Grant from the National Medical Research Council of Singapore (NMRC/BNIG/2005/2013). AT Irving is supported by a New Investigator's Grant from the National Medical Research Council of Singapore (NMRC/BNIG/2040/2015).

\section{Compliance with ethical standards}

Conflict of interest The authors declare that they have no competing interests.

\section{References}

Ahn M, Cui J, Irving AT, Wang LF (2016) Unique loss of the PYHIN gene family in bats amongst mammals: implications for inflammasome sensing. Sci Rep 6:21722. https://doi.org/10.1038/ srep21722

Ahn M et al (2019) Dampened NLRP3-mediated inflammation in bats and implications for a special viral reservoir host. Nat Microbiol 4: 789-799. https://doi.org/10.1038/s41564-019-0371-3

Ball HC, Levari-Shariati S, Cooper LN, Aliani M (2018) Comparative metabolomics of aging in a long-lived bat: insights into the physiology of extreme longevity. PLoS One 13:e0196154. https://doi.org/ 10.1371/journal.pone.0196154

Beere HM, Wolf BB, Cain K, Mosser DD, Mahboubi A, Kuwana T, Tailor P, Morimoto RI, Cohen GM, Green DR (2000) Heat-shock 
protein 70 inhibits apoptosis by preventing recruitment of procaspase-9 to the Apaf-1 apoptosome. Nat Cell Biol 2:469-475. https://doi.org/10.1038/35019501

Bloyet LM, Welsch J, Enchery F, Mathieu C, de Breyne S, Horvat B, Grigorov B, Gerlier D (2016) Requirement of HSP90 chaperoning in addition to phosphoprotein for folding but not for supporting enzymatic activities of measles and Nipah virus L polymerases. J Virol 90:6642-6656. https://doi.org/10.1128/JVI.00602-16

Bozek K, Khrameeva EE, Reznick J, Omerbašić D, Bennett NC, Lewin GR, Azpurua J, Gorbunova V, Seluanov A, Regnard P, Wanert F, Marchal J, Pifferi F, Aujard F, Liu Z, Shi P, Pääbo S, Schroeder F, Willmitzer L, Giavalisco P, Khaitovich P (2017) Lipidome determinants of maximal lifespan in mammals. Sci Rep 7:5. https://doi.org/ 10.1038/s41598-017-00037-7

Brunet-Rossinni AK (2004) Reduced free-radical production and extreme longevity in the little brown bat (Myotis lucifugus) versus two nonflying mammals. Mech Ageing Dev 125:11-20

Castello A, Fischer B, Frese CK, Horos R, Alleaume AM, Foehr S, Curk T, Krijgsveld J, Hentze MW (2016) Comprehensive identification of RNA-binding domains in human cells. Mol Cell 63:696-710. https://doi.org/10.1016/j.molcel.2016.06.029

Chua KB, Lek Koh C, Hooi PS, Wee KF, Khong JH, Chua BH, Chan YP, Lim ME, Lam SK (2002) Isolation of Nipah virus from Malaysian Island flying-foxes. Microbes Infect / Institut Pasteur 4:145-151

Crameri G, Todd S, Grimley S, McEachern JA, Marsh GA, Smith C, Tachedjian M, de Jong C, Virtue ER, Yu M, Bulach D, Liu JP, Michalski WP, Middleton D, Field HE, Wang LF (2009) Establishment, immortalisation and characterisation of pteropid bat cell lines. PLoS One 4:e8266. https://doi.org/10.1371/journal.pone. 0008266

Davies KT, Tsagkogeorga G, Bennett NC, Davalos LM, Faulkes CG, Rossiter SJ (2014) Molecular evolution of growth hormone and insulin-like growth factor 1 receptors in long-lived, small-bodied mammals. Gene 549:228-236. https://doi.org/10.1016/j.gene.2014. 07.061

Foss DL, Baarsch MJ, Murtaugh MP (1998) Regulation of hypoxanthine phosphoribosyltransferase, glyceraldehyde-3-phosphate dehydrogenase and beta-actin mRNA expression in porcine immune cells and tissues. Anim Biotechnol 9:67-78. https://doi.org/10.1080/ 10495399809525893

Galbadage T, Hartman PS (2008) Repeated temperature fluctuation extends the life span of Caenorhabditis elegans in a daf-16-dependent fashion. Mech Ageing Dev 129:507-514. https://doi.org/10.1016/j. $\operatorname{mad} .2008 .04 .012$

Garg D, Skouloubris S, Briffotaux J, Myllykallio H, Wade RC (2015) Conservation and role of electrostatics in thymidylate synthase. Sci Rep 5:17356. https://doi.org/10.1038/srep17356

Geller R, Taguwa S, Frydman J (2012) Broad action of Hsp90 as a host chaperone required for viral replication. Biochim Biophys Acta Mol Cell Res 1823:698-706

Ghosh S, Chan CK (2016) Analysis of RNA-Seq data using TopHat and cufflinks. Methods Mol Biol 1374:339-361. https://doi.org/10. 1007/978-1-4939-3167-5 18

Gille C, Frommel C (2001) STRAP: editor for structural alignments of proteins. Bioinformatics 17:377-378

Glotzer JB, Saltik M, Chiocca S, Michou A-I, Moseley P, Cotten M (2000) Activation of heat-shock response by an adenovirus is essential for virus replication. Nature 407:207-211

Grant RJ, Banyard AC, Barrett T, Saliki JT, Romero CH (2009) Real-time RT-PCR assays for the rapid and differential detection of dolphin and porpoise morbilliviruses. J Virol Methods 156:117-123. https:// doi.org/10.1016/j.jviromet.2008.11.008

Guindon S, Dufayard JF, Lefort V, Anisimova M, Hordijk W, Gascuel O (2010) New algorithms and methods to estimate maximumlikelihood phylogenies: assessing the performance of PhyML 3.0. Syst Biol 59:307-321. https://doi.org/10.1093/sysbio/syq010
Hall LS, Saunders L, Richards GC (2000) Flying foxes: fruit and blossom bats of Australia. Australian natural history series. UNSW Press, Sydney

Halpin K, Young PL, Field HE, Mackenzie JS (2000) Isolation of Hendra virus from pteropid bats: a natural reservoir of Hendra virus. J Gen Virol 81:1927-1932

Han Y, Zheng G, Yang T, Zhang S, Dong D, Pan YH (2015) Adaptation of peroxisome proliferator-activated receptor alpha to hibernation in bats. BMC Evol Biol 15:88. https://doi.org/10.1186/s12862-0150373-6

Hayashida N, Fujimoto M, Tan K, Prakasam R, Shinkawa T, Li L, Ichikawa H, Takii R, Nakai A (2010) Heat shock factor 1 ameliorates proteotoxicity in cooperation with the transcription factor NFAT. EMBO J 29:3459-3469. https://doi.org/10.1038/emboj. 2010.225

Heidler T, Hartwig K, Daniel H, Wenzel U (2010) Caenorhabditis elegans lifespan extension caused by treatment with an orally active ROSgenerator is dependent on DAF-16 and SIR-2.1. Biogerontology 11: 183-195. https://doi.org/10.1007/s10522-009-9239-x

Hill JE, Smith JD (1984) Bats : a natural history. British Museum (Natural History), London

Hu B, Chmura AA, Li J, Zhu G, Desmond JS, Zhang Y, Zhang W, Epstein JH, Daszak P, Shi Z (2014) Detection of diverse novel astroviruses from small mammals in China. J Gen Virol 95:24422449. https://doi.org/10.1099/vir.0.067686-0

Huang KJ, Su IJ, Theron M, Wu YC, Lai SK, Liu CC, Lei HY (2005) An interferon- $\gamma$-related cytokine storm in SARS patients. J Med Virol 75:185-194

Hughes GM, Leech J, Puechmaille SJ, Lopez JV, Teeling EC (2018) Is there a link between aging and microbiome diversity in exceptional mammalian longevity? PeerJ 6:e4174. https://doi.org/10.7717/peerj. 4174

Ithete NL, Stoffberg S, Corman VM, Cottontail VM, Richards LR, Schoeman MC, Drosten C, Drexler JF, Preiser W (2013) Close relative of human Middle East respiratory syndrome coronavirus in bat, South Africa. Emerg Infect Dis 19:1697-1699. https://doi. org/10.3201/eid1910.130946

Kosir R, Acimovic J, Golicnik M, Perse M, Majdic G, Fink M, Rozman D (2010) Determination of reference genes for circadian studies in different tissues and mouse strains. BMC Mol Biol 11:60. https:// doi.org/10.1186/1471-2199-11-60

Lee TY, Chang WC, Hsu JB, Chang TH, Shien DM (2012) GPMiner: an integrated system for mining combinatorial cis-regulatory elements in mammalian gene group. BMC Genomics 13(Suppl 1):S3. https:// doi.org/10.1186/1471-2164-13-S1-S3

Leroy EM, Kumulungui B, Pourrut X, Rouquet P, Hassanin A, Yaba P, Délicat A, Paweska JT, Gonzalez JP, Swanepoel R (2005) Fruit bats as reservoirs of Ebola virus. Nature 438:575-576. https://doi.org/10. $1038 / 438575 a$

Li W, Shi Z, Yu M, Ren W, Smith C, Epstein JH, Wang H, Crameri G, Hu Z, Zhang H, Zhang J, McEachern J, Field H, Daszak P, Eaton BT, Zhang S, Wang LF (2005) Bats are natural reservoirs of SARS-like coronaviruses. Science 310:676-679. https://doi.org/10.1126/ science. 1118391

Maina JN, Thomas SP, Hyde DM (1991) A morphometric study of the lungs of different sized bats: correlations between structure and function of the chiropteran lung. Philos Trans R Soc Lond Ser B Biol Sci 333:31-50. https://doi.org/10.1098/rstb.1991.0059

McNab BK (1966) An analysis of the body temperatures of birds. Condor 68:47-55

Miller MR, McMinn RJ, Misra V, Schountz T, Muller MA, Kurth A, Munster VJ (2016) Broad and temperature independent replication potential of filoviruses on cells derived from old and New World bat species. J Infect Dis 214:S297-S302. https://doi.org/10.1093/infdis/ jiw199 
Minois N, Guinaudy MJ, Payre F, Le Bourg E (1999) HSP70 induction may explain the long-lasting resistance to heat of Drosophila melanogaster having lived in hypergravity. Mech Ageing Dev 109: $65-77$

Morley JF, Morimoto RI (2004) Regulation of longevity in Caenorhabditis elegans by heat shock factor and molecular chaperones. Mol Biol Cell 15:657-664

Mosser DD, Caron AW, Bourget L, Denis-Larose C, Massie B (1997) Role of the human heat shock protein hsp70 in protection against stress-induced apoptosis. Mol Cell Biol 17:5317-5327

Munshi-South J, Wilkinson GS (2010) Bats and birds: exceptional longevity despite high metabolic rates. Ageing Res Rev 9:12-19. https://doi.org/10.1016/j.arr.2009.07.006

Nagy P, Wang R, Pogany J, Hafren A, Makinen K (2011) Emerging picture of host chaperone and cyclophilin roles in RNA virus replication. Virology 411:374-382

$\mathrm{Ng} \mathrm{JH}$ et al (2016) Evolution and comparative analysis of the bat MHC-I region. Sci Rep 6:21256. https://doi.org/10.1038/srep21256

Nowak RM (1999) Walker's mammals of the world. 6th edn. Johns Hopkins University Press, Baltimore

O'Mara MT, Wikelski M, Voigt CC, ter Maat A, Pollock HS, Burness G, Desantis LM, Dechmann DKN (2017) Cyclic bouts of extreme bradycardia counteract the high metabolism of frugivorous bats. Elife 6 . https://doi.org/10.7554/eLife.26686

O'Shea TJ et al (2014) Bat flight and zoonotic viruses. Emerg Infect Dis 20:741-745. https://doi.org/10.3201/eid2005.130539

Pandey P, Saleh A, Nakazawa A, Kumar S, Srinivasula SM, Kumar V, Weichselbaum R, Nalin C, Alnemri ES, Kufe D, Kharbanda S (2000) Negative regulation of cytochrome c-mediated oligomerization of Apaf-1 and activation of procaspase- 9 by heat shock protein 90. EMBO J 19:4310-4322. https://doi.org/10.1093/emboj/19.16. 4310

Peng X et al (2017) Flight is the key to postprandial blood glucose balance in the fruit bats Eonycteris spelaea and Cynopterus sphinx. Ecol Evol 7:8804-8811. https://doi.org/10.1002/ece3.3416

Perez VI, Buffenstein R, Masamsetti V, Leonard S, Salmon AB, Mele J, Andziak B, Yang T, Edrey Y, Friguet B, Ward W, Richardson A, Chaudhuri A (2009) Protein stability and resistance to oxidative stress are determinants of longevity in the longest-living rodent, the naked mole-rat. Proc Natl Acad Sci U S A 106:3059-3064. https://doi.org/10.1073/pnas.0809620106

Pfaffl MW (2001) A new mathematical model for relative quantification in real-time RT-PCR. Nucleic Acids Res 29:e45

Phillips AM, Gonzalez LO, Nekongo EE, Ponomarenko AI, McHugh SM, Butty VL, Levine SS, Lin YS, Mirny LA, Shoulders MD (2017) Host proteostasis modulates influenza evolution. Elife 6. https://doi.org/10.7554/eLife.28652

Plowright RK, Eby P, Hudson PJ, Smith IL, Westcott D, Bryden WL, Middleton D, Reid PA, McFarlane RA, Martin G, Tabor GM, Skerratt LF, Anderson DL, Crameri G, Quammen D, Jordan D, Freeman P, Wang LF, Epstein JH, Marsh GA, Kung NY, McCallum H (2015) Ecological dynamics of emerging bat virus spillover. Proc Biol Sci 282:20142124. https://doi.org/10.1098/ rspb.2014.2124

Podlutsky AJ, Khritankov AM, Ovodov ND, Austad SN (2005) A new field record for bat longevity. J Gerontol Ser A Biol Med Sci 60: 1366-1368

Prasad KV, Taiyab A, Jyothi D, Srinivas UK, Sreedhar AS (2007) Heat shock transcription factors regulate heat induced cell death in a rat histiocytoma. J Biosci 32:585-593

Reyes-del Valle J, Chávez-Salinas S, Medina F, del Angel RM (2005) Heat shock protein 90 and heat shock protein 70 are components of dengue virus receptor complex in human cells. J Virol 79:45574567

Rodriguez KA, Valentine JM, Kramer DA, Gelfond JA, Kristan DM, Nevo E, Buffenstein R (2016) Determinants of rodent longevity in the chaperone-protein degradation network. Cell Stress Chaperones 21:453-466. https://doi.org/10.1007/s12192-016-0672-x

Salmon AB, Leonard S, Masamsetti V, Pierce A, Podlutsky AJ, Podlutskaya N, Richardson A, Austad SN, Chaudhuri AR (2009) The long lifespan of two bat species is correlated with resistance to protein oxidation and enhanced protein homeostasis. FASEB J 23: 2317-2326. https://doi.org/10.1096/fj.08-122523

Salway KD, Gallagher EJ, Page MM, Stuart JA (2011) Higher levels of heat shock proteins in longer-lived mammals and birds. Mech Ageing Dev 132:287-297. https://doi.org/10.1016/j.mad.2011.06. 002

Shurtleff AC, Costantino JA, Tritsch SR, Retterer C, Spurgers KB, Bavari S (2014) HSPA5 is an essential host factor for Ebola virus infection. Antivir Res 109:171-174

Singh R et al (2006) Heat-shock protein 70 genes and human longevity. Ann N Y Acad Sci 1067:301-308

Srivastava P (2002) Roles of heat-shock proteins in innate and adaptive immunity. Nat Rev Immunol 2:185-194

Swindell WR (2009) Heat shock proteins in long-lived worms and mice with insulin/insulin-like signaling mutations. Aging (Albany NY) 1: 573-577. https://doi.org/10.18632/aging.100058

Tanaka T, Shibazaki A, Ono R, Kaisho T (2014) HSP70 mediates degradation of the p65 subunit of nuclear factor kappaB to inhibit inflammatory signaling. Sci Signal 7:ra119. https://doi.org/10.1126/ scisignal.2005533

Walker GA, Lithgow GJ (2003) Lifespan extension in C. elegans by a molecular chaperone dependent upon insulin-like signals. Aging Cell 2:131-139. https://doi.org/10.1046/j.1474-9728.2003.00045.x

Wilkinson GS, Adams DM (2019) Recurrent evolution of extreme longevity in bats. Biol Lett 15:20180860. https://doi.org/10.1098/rsbl. 2018.0860

Wynne JW, Shiell BJ, Marsh GA, Boyd V, Harper JA, Heesom K, Monaghan P, Zhou P, Payne J, Klein R, Todd S, Mok L, Green D, Bingham J, Tachedjian M, Baker ML, Matthews D, Wang LF (2014) Proteomics informed by transcriptomics reveals Hendra virus sensitizes bat cells to TRAIL-mediated apoptosis. Genome Biol 15:532. https://doi.org/10.1186/PREACCEPT-1718798964145132

Yang Z (2007) PAML 4: phylogenetic analysis by maximum likelihood. Mol Biol Evol 24:1586-1591. https://doi.org/10.1093/molbev/ msm088

Yin Q, Zhu L, Liu D, Irwin DM, Zhang S, Pan YH (2016) Molecular evolution of the nuclear factor (erythroid-derived 2)-like 2 gene Nrf2 in Old World fruit bats (Chiroptera: Pteropodidae). PLoS One 11: e0146274. https://doi.org/10.1371/journal.pone.0146274

Young PL, Halpin K, Selleck PW, Field H, Gravel JL, Kelly MA, Mackenzie JS (1996) Serologic evidence for the presence in Pteropus bats of a paramyxovirus related to equine morbillivirus. Emerg Infect Dis 2:239-240. https://doi.org/10.3201/eid0203. 960315

Zhang Y, Chou SD, Murshid A, Prince TL, Schreiner S, Stevenson MA, Calderwood SK (2011) The role of heat shock factors in stressinduced transcription. Methods Mol Biol 787:21-32. https://doi. org/10.1007/978-1-61779-295-3 2

Zhang G, Cowled C, Shi Z, Huang Z, Bishop-Lilly KA, Fang X, Wynne JW, Xiong Z, Baker ML, Zhao W, Tachedjian M, Zhu Y, Zhou P, Jiang X, Ng J, Yang L, Wu L, Xiao J, Feng Y, Chen Y, Sun X, Zhang Y, Marsh GA, Crameri G, Broder CC, Frey KG, Wang LF, Wang J (2013) Comparative analysis of bat genomes provides insight into the evolution of flight and immunity. Science 339:456-460. https:// doi.org/10.1126/science.1230835

Zhang B, Peng Y, Zheng J, Liang L, Hoffmann AA, Ma CS (2016) Response of heat shock protein genes of the oriental fruit moth under diapause and thermal stress reveals multiple patterns dependent on the nature of stress exposure. Cell Stress Chaperones 21:653-663. https://doi.org/10.1007/s12192-016-0690-8 
Zhang Q, Zeng LP, Zhou P, Irving AT, Li S, Shi ZL, Wang LF (2017) IFNAR2-dependent gene expression profile induced by IFN-alpha in Pteropus alecto bat cells and impact of IFNAR2 knockout on virus infection. PLoS One 12:e0182866. https://doi.org/10.1371/ journal.pone. 0182866

Zhao Y et al (2005) Lifespan extension and elevated hsp gene expression in Drosophila caused by histone deacetylase inhibitors. J Exp Biol 208:697-705. https://doi.org/10.1242/jeb.01439

Zhou P, Cowled C, Mansell A, Monaghan P, Green D, Wu L, Shi Z, Wang LF, Baker ML (2014) IRF7 in the Australian black flying fox, Pteropus alecto: evidence for a unique expression pattern and functional conservation. PLoS One 9:e103875. https://doi.org/10.1371/ journal.pone. 0103875

Zhou P, Tachedjian M, Wynne JW, Boyd V, Cui J, Smith I, Cowled C, Ng JHJ, Mok L, Michalski WP, Mendenhall IH, Tachedjian G, Wang
LF, Baker ML (2016) Contraction of the type I IFN locus and unusual constitutive expression of IFN-alpha in bats. Proc Natl Acad Sci U S A 113:2696-2701. https://doi.org/10.1073/pnas. 1518240113

Zhu HC, Chu DKW, Liu W, Dong BQ, Zhang SY, Zhang JX, Li LF, Vijaykrishna D, Smith GJD, Chen HL, Poon LLM, Peiris JSM, Guan Y (2009) Detection of diverse astroviruses from bats in China. J Gen Virol 90:883-887. https://doi.org/10.1099/vir.0. 007732-0

Publisher's note Springer Nature remains neutral with regard to jurisdictional claims in published maps and institutional affiliations. 